\title{
Priority water research questions for South Africa developed through participatory processes
}

\author{
RM Siebrits ${ }^{1}$, K Winter $^{1 *}$, J Barnes ${ }^{2}$, MC Dent ${ }^{3}$, G Ekama $^{4}$, M Ginster ${ }^{5}$, J Harrison ${ }^{6}$, B Jackson ${ }^{7}$, I Jacobs $^{8}$, \\ A Jordaan ${ }^{9}$, HC Kasan $^{10}$, W Kloppers ${ }^{11}$, R le Roux ${ }^{12}$, J Maree ${ }^{13}$, MNB Momba $^{13}$, AV Munnik ${ }^{14}, \mathrm{~J}^{\prime} \mathrm{K}^{\prime} \mathrm{Keeffe}^{15}$, R Schulze ${ }^{3}$, \\ M Silberbauer ${ }^{16}$, D Still' ${ }^{17}$ and JE van Zyl ${ }^{4}$ \\ 'Department of Environmental and Geographical Science, Faculty of Science, University of Cape Town, Private Bag X3, Rondebosch, 7701, South Africa \\ ${ }^{2}$ Community Health, Faculty of Medicine and Health Sciences, Stellenbosch University, PO Box 19063, Tygerberg, Cape Town, 7505, South Africa \\ ${ }^{3}$ School of Agricultural, Earth and Environmental Sciences, University of KwaZulu-Natal, Private Bag X01, Scottsville, 3209, South Africa \\ ${ }^{4}$ Department of Civil Engineering, Faculty of Engineering and the Built Environment, University of Cape Town, Private Bag X3, \\ Rondebosch, 7701, South Africa \\ ${ }^{5}$ Sasol Group Services, PO Box 5486, Johannesburg, 2000, South Africa \\ ${ }^{6}$ eThekwini Water and Sanitation, PO Box 1038, Durban, 4000, South Africa \\ 'Inkomati Catchment Management Agency, 8th floor, Maxsa Building, 13 Streak Street, Nelspruit, 1200, South Africa \\ ${ }^{8}$ Water Research Commission, Private Bag X03, Gezina, Pretoria, 0031, South Africa \\ ${ }^{9}$ Disaster Management Training and Education Centre for Africa, Faculty of Natural and Agricultural Sciences, University of the Free State, \\ Bloemfontein, 9300, South Africa \\ ${ }^{10}$ Rand Water, PO Box 1127, Johannesburg, 2000, South Africa \\ "Resource Protection, Western Cape Department of Water Affairs, Private Bag X16, Sanlamhof, Cape Town, 7532, South Africa \\ ${ }^{12}$ Breede Overberg Catchment Management Agency, 51 Baring Street, Worcester, 6849, South Africa \\ ${ }^{14}$ Independent Research for Water, Climate and Environmental Justice, 258 Highland Road, Kensington, 2192, South Africa \\ ${ }^{13}$ Department of Environmental, Water and Earth Sciences, Faculty of Science, Tshwane University of Technology, Private Bag X680, \\ Arcadia Campus, Pretoria, 0001, South Africa \\ ${ }^{15}$ Environmental Learning Research Centre, Education Department, Rhodes University, PO Box 94, Grahamstown, 6140, South Africa \\ ${ }^{16}$ Resource Quality Services, Department of Water Affairs, Private Bag X313, Pretoria 0001, South Africa \\ 17Partners in Development, PO Box 11431, Dorpspruit, 3206, South Africa
}

\begin{abstract}
This paper describes a collaborative process of identifying and prioritising current and future water research questions from a wide range of water specialists within South Africa. Over 1600 questions were collected, reduced in number and prioritised by specialists working in water research and practice. A total of 59 questions were finally proposed as an outcome of the study and are categorised under the themes of change, data, ecosystems, governance, innovation and resources. The questions range in scale, challenge and urgency, and are also aligned with prevailing paradigms in water research. The majority of the questions dealt with relatively short- to medium-term research requirements and most focused on immediate issues such as water supply, service delivery and technical solutions. Formulations of long-term research questions were sparse, partly because some of the principles and methods used in this study were difficult to apply in the South African context, and also because researchers are influenced by addressing what are believed to be the more immediate, short-term water-related challenges in South Africa. This is the first initiative of its kind to produce a comprehensive and inclusive list of research priorities for water in South Africa.
\end{abstract}

Keywords: research, questions, collaboration, prioritisation, South Africa

\section{INTRODUCTION}

\section{What we ought to do}

The first significant effort to co-ordinate water research in South Africa began with the promulgation of the Water Research Act (Act No. 34 of 1971) (Republic of South Africa, 1971), arguably one of the most important initiatives to shape the development of water research in the country. Provisions in this Act also resulted in the establishment of the Water Research Commission (WRC). Since 1971, the WRC has used public funds to support water research projects, which is

\footnotetext{
* To whom all correspondence should be addressed.

酉 +27 21650 2873; e-mail: kevin.winter@uct.ac.za

Received 23 July 2013; accepted in revised form 28 February 2014.
}

evident in the plethora of water research activities and publications. While the national research output of the WRC accounts for a substantial proportion of publications, other institutes such as government departments, national science councils, universities, private consultancies, civic groups and nongovernmental organisations also contribute to water research.

The National Water Act (No. 36 of 1998) (Republic of South Africa, 1998) is regarded as an important departure from the idea of riparian ownership of water (Tewari, 2009). Few countries have had the opportunity to radically transform water resource legislation and research in order to address fundamental socio-economic needs, and enable equity and social justice. Many of the principles in the Act represent a mix of modernist and postmodernist paradigms, and Funke (2007, p. 66) states that 'in many ways this shift in water policy mimics the shift in thinking in certain progressive research circles: from one which focuses on the physical laws of nature and the principles that 
drive society and what we are capable of doing through technological intervention, toward one which is driven by a strong set of values and the question of what ought we to do?'

This paper considers this question further in suggesting that one way of contributing to the 'ought' is to develop a series of water research questions that demand priority attention. Thus the paper describes the process of identifying and evaluating research questions, as proposed by researchers active in scientific research and water sector management in South Africa, that seek to address current and anticipated future issues and challenges related to both theoretical and practical needs.

Scientific research, in the context of this paper, is the 'human activity that aims at contributing to a coherent body of knowledge in a novel way by adopting a critical method' (Bortolotti, 2008 p. 15).Prominent views also state that knowledge and information from research ought to contribute to sustainable development (Pullin et al., 2009; Turton, 2009; Barbier and Homer-Dixon, 1996; Homer-Dixon, 1995). The solution to problems, particularly those 'wicked' problems that are complex and systemic, should be through innovation, and the generation of ideas and knowledge (Barbier and Homer-Dixon, 1996; Homer-Dixon, 1995). Strengthening ideas, solving problems and managing development directives, while balancing societal and environmental demands, depends on the application of appropriate knowledge and human capacity. The emphasis here lies in how we measure knowledge gaps, plan research, allocate resources and implement adaptive capacity.

\section{METHODS}

\section{Horizon scanning}

The three broad stages of the adopted horizon scanning method are question collection, categorisation and prioritisation. These are most often classified according to fields and disciplines, and prioritised according to their urgency and relevance to society (Sutherland et al., 2011b). This method is pertinent to embracing on-going and widespread social transformation in South Africa, so the approach was focused on developing these questions through collaborative, multi-stakeholder processes that identify and examine threats or trends in society, the environment or a sector, and identify needs that will enable the appropriate management (Shackleton et al., 2011; Sutherland and Woodroof, 2009).

The uses and applications of horizon scanning '...include strategy making, policy making, risk management, threat identification and research prioritisation' (Sutherland and Woodroof, 2009 p. 525). The main challenges of horizon scanning are obtaining credible and reliable evidence, and designing and adopting objective, collaborative, scalable, transparent and efficient methods. Overall, 'the objective is not to predict the future but to assist current decision-makers to produce strategies and plans that are sufficiently flexible and adaptable. 'Scientists must also have foresight regarding trends and changes, using horizon scanning as a tool, and constantly adapt their role in responding to these changes (Shackelton et al., 2011). Forecasting and science planning and horizon scanning are relevant methods and activities in the arenas of knowledge management, strategic research planning and sustainable research management (King and Thomas, 2007). The European Environment Agency (2001) identified two key lessons in its analysis of how preventable environmental problems or issues could have been avoided, mitigated or managed through appropriate and timely research. These lessons were to 'research and monitor for early warnings' and 'search out and address blind spots and gaps in scientific knowledge' (Sutherland and Woodroof, 2009 p. 523).

Horizon scanning in South African water research follows the steps of(I) scoping the issue; (ii) gathering information; (iii) spotting signals; (iv) watching trends; (v) making sense of the future; and (vi) agreeing on the response (Sutherland and Woodroof, 2009 p. 525). A similar research method and process helped identify water research questions for the United Kingdom (Brown et al., 2010). The researchers state that 'several recent studies have emphasised the need for a more integrated process in which researchers, policy makers and practitioners interact to identify research priorities.'

The research presented in this paper aims to produce a similar output and to motivate for a system where regular horizon scanning activities are undertaken, reviewed and published (Pretty et al., 2010 and Sutherland et al., 2011a). Horizon scanning could potentially enhance the water research and in turn water management futures of South Africa by providing a co-ordinated, evidence-based approach towards water research, aiding in the sustainability of research as an undertaking and encouraging innovation in water research. 'The practice of foresight plays an important role in science and technology policies' (Treyer, 2009 p. 353) thereby encouraging actors to look further into the future and develop appropriate, informed research strategies and policies.

\section{Conceptual basis}

The three main steps in building the research question database were: (i) identify and create a collaborative stakeholder network; (ii) collect data from individuals in this network regarding their research expertise, opinions on research considerations and research questions; and (iii) analyse this data by allowing the network to deliberate responses and produce a final set of results of research opinion and questions.

A substantial taxonomy of horizon scanning methods is available for identifying and prioritising future research questions, scenarios and needs, including open forums, trend analysis, questionnaire and expert consultation (Sutherland and Woodroof, 2009). The principle approach of the current study focused on stakeholder identification and enlistment. This catch-all effort, however, is restricted to the field of water research, and subsequent questionnaires were directed to extracting participant expertise and research experience in water research. The principle of inclusivity, especially in encouraging the participation of smaller, peripheral or multidisciplinary research stakeholders, is critical to furthering the development and stimulation of research in South Africa.

The final component of the study comprised a specialist workshop. Experts, as identified by an initial survey, were invited to participate in this exercise for the purpose of validating and commenting on the results, and to provide credibility to the research questions that were submitted to the database, as in similar studies elsewhere (Sutherland et al., 2011a; Sutherland and Woodroof, 2009). However, in this study the interest lay in the methods of supporting research and in generating a substantial body of research priorities, rather than creating questions for evidence-based policy. Participants were invited, as per international practice, to contribute to this paper as co-authors due to their workshop and editing contributions. 


\section{Building a collaborative network}

As mentioned, the intention was always to involve a wide range of stakeholders with an interest in water and water research, and to engage participants through the 'voice' of a research initiative, rather than through the researchers' own. The research enterprise was named Aqua d'UCT with the tag-line of 'Integrating Water Research'. All communication with stakeholders was organised through the 'voice' of Aqua d'UCT, but also kept as 'human' and 'interpersonal' as possible.

The domain (www.aquaduct.org.za) became the online presence for the study. Participants could sign up to contribute to surveys, receive newsletters or updates, view and download data, obtain results from the research, find more information about the research and communicate with the study team. The fundamental principle behind the creation of an online platform was that more stakeholders could be reached, at a faster rate and at lower cost. A marketing campaign informed stakeholders and invited them to participate. Activities included conference presentations, networking, e-mailing key networks or groups and social agents or activators, and linking the site to other water-related sites. Pilot surveys, polls and communications tested the effectiveness of methods for engagement and response. The website was constantly updated and enhanced during this process. Stakeholders were able to register for the newsletter and participate in the research via a simple web-based form.

The research was communicated to a wide spread of institutions, water-related specialisations and sectors, networks and the research community in this manner, in order to create a diverse, multi-disciplinary network. The use of digital technology and effective communication with many other networks enabled a large number of stakeholders to be contacted at low cost and high scalability. The database continued to grow throughout this period and after the surveys.

\section{Within the network}

Lessons learned from pilot activities and suggestions were incorporated in the production of the main survey. A research team member telephoned contacts on the database. They were alerted to the study, its objectives and the length of time required for completing the survey. The option of doing the survey over the phone or online was also offered to them. Telephone calls were made in May and June 2012. The purposes of this survey were to gather the research and professional profile of the participant; conduct a scan on present and future challenges; and gather research questions and associated details to be researched.

The official, main survey entitled 'Priority questions for water research 2012 (Aqua d'UCT \& Water Research Commission)' was released to the stakeholders on 21 May 2012 and closed on 6 July 2012. It comprised 3 main parts: an introduction followed by brief questions to provide the research/professional profile of the participant; the central question gathering section; and requests for opinions and comments.

The submitted questions, being the key elements of this exercise, were initially reviewed by a team of researchers to remove obvious duplicates and improve the text, grammar, spelling and style. The questions were also scanned to determine whether obvious knowledge exists concerning the topic of research and an estimation of the time period required for completing the proposed research question. A combination of these activities reduced the volume of questions. Finally, the questions were categorised into 6 main integrated themes prior to the specialist workshop. These themes were decided upon through specialist consultation and included elements of the WRC impact areas and the National Water Resource Strategy priorities (Department of Water Affairs, 2012).

Specialist participants, chosen for their experience in their field or within water-related research, were identified from amongst the respondents by using their profile of answers provided in the survey and through consultation with the project manager and the WRC. Water specialists were also selected based on their organisational involvement, disciplinary interests and experience.

Questions from the main survey were distributed to the specialist group upon their acceptance of an invitation to the 'Water research horizon scanning workshop' which was held during October 2012 in Cape Town. Substantial, early discussions with delegates and the workshop facilitators were held in order to create the appropriate workshop programme and pre-event participation. This was aimed at eliciting comment and clarifying the study to delegates.

The central aim over the 2 days was to reduce the question dataset by prioritising questions within the 6 themes as described earlier. The final list of questions became the main workshop output and was named the 'Priority water research questions in South Africa 2012'. These were then distributed to delegates. A final distribution of the results and feedback was made to all delegates in December 2012 with an invitation for further comment including prompts about the future direction of the study.

\section{Summary of stakeholders and participants}

By December 2012 there were 2260 unique stakeholders on the database, all of whom were gathered at minimal cost over 15 months of operation. The stakeholders in the database signed up with Aqua d'UCT for numerous reasons. Some simply wanted to remain informed of the process and results. Others saw an opportunity to participate in the surveys and discussions, while others used the portal to ask for further information about water research.

The diversity of stakeholders within the database was seen in their involvement with a range of organisations or affiliations. Many were recommended by peers or were on an openaccess contact list, had attended a relevant water-related event or read and followed online calls. Figure 1 presents the organisations in the database. Overall, stakeholders in the database were affiliated to 572 organisations or institutions.

The distribution of the sector affiliations is an important factor. As stated earlier, the intention was for the overall research to be as integrated, multi-disciplinary and inclusive as possible. The fact that research organisations or institutions (university or research council) hold places 2 to 11 (Fig. 1) underscores the relevance of this study to these institutions but also identifies where the majority of research activity occurs in South Africa.

\section{Questioning the population}

Overall, 1075 stakeholders were contacted and spoken to directly via individual telephone calls during May and June 2012 to be alerted to the survey. Along with these, 503 more were contacted via e-mail only. The survey link was accessed 1028 times during its live phase. There were 387 incomplete surveys (ones where at least the first input page was completed but not the entire survey). By the time the main survey closed in July 2012, there were 641 fully completed responses. One 


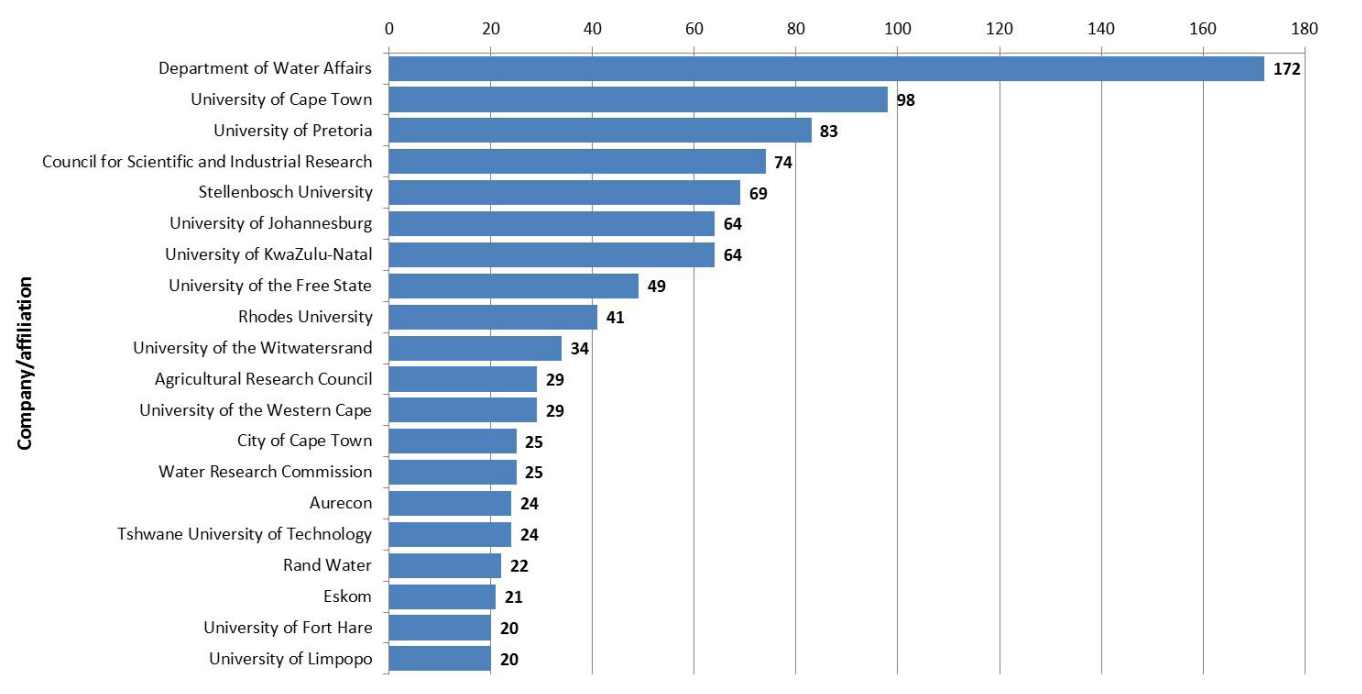

Figure 1

Distribution of database stakeholder organisation or affiliation (responses $=2080$; unique entities $=$ 572; only organisations/ affiliations with 20 or more counts displayed)

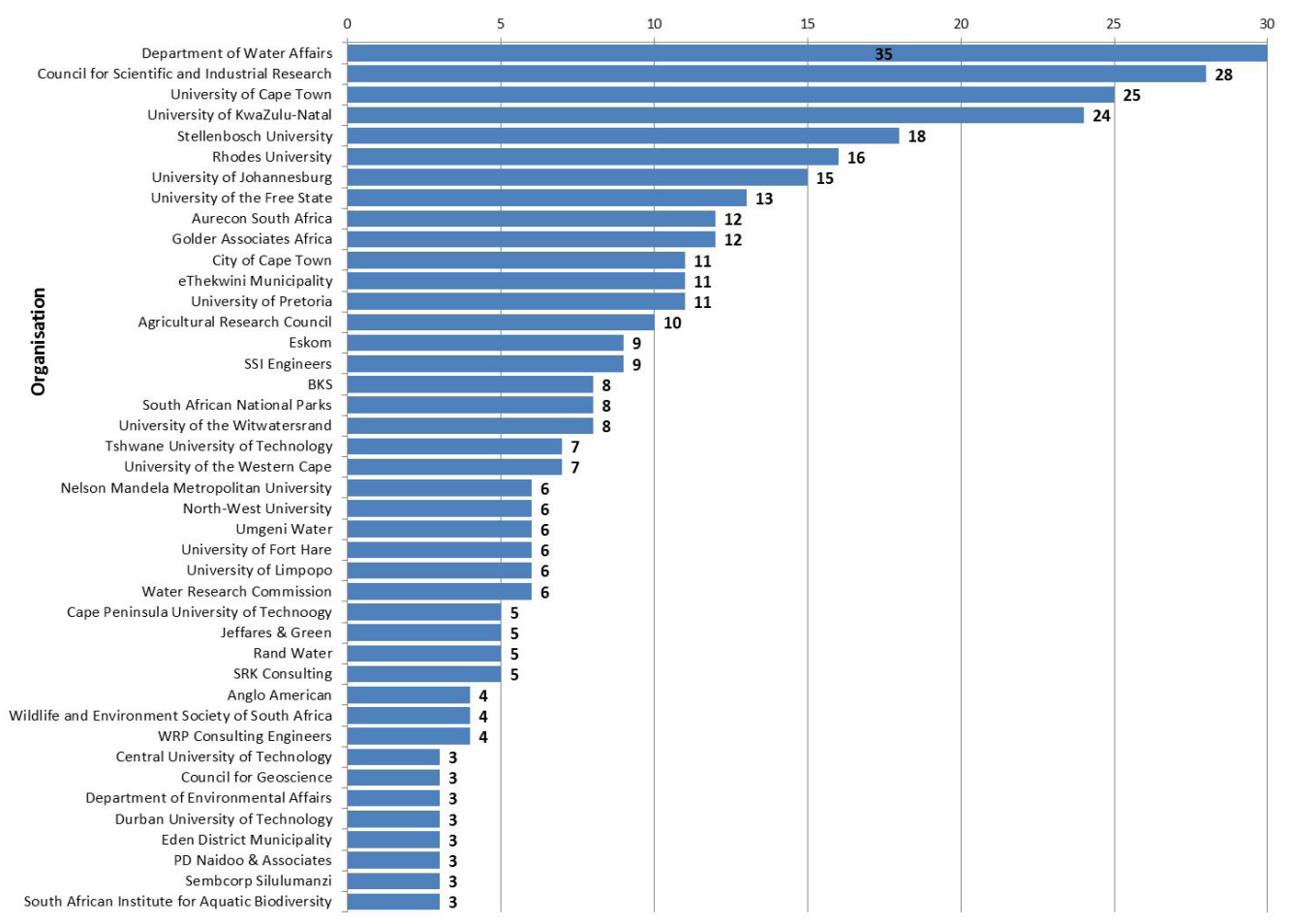

Figure 2

Distribution of survey respondent organisation or affiliation $(n=641$; unique $=221$; no response $=50$; only organisations with 3 or more respondents displayed)

concern expressed by many participants was that although the survey was estimated to take 20 minutes to complete, feedback from participants suggested that an average survey completion time ranged from 30-40 minutes.

Figure 2 presents the main survey participant affiliations or organisations (592 responses, 221 unique organisations).

The national authority provided the most survey respondents with universities and state research institutions taking $2^{\text {nd }}$ to $6^{\text {th }}$ place. There was fair diversity in the remaining top respondent affiliation with a few private entities and consultancies being represented along with other environmental organisations, other universities and utilities.

Respondents were asked to indicate their years of experience in the current discipline in which they practise (Fig. 3), and the top 4 counts were 5 (53), 15 (40), 2 (39) and 10 (35) years of experience. When analysed in decades of experience, the following respondent counts were observed (in brackets): $0-1$ (297), 1-2 (188), 2-3 (86), 3-4 (51) and 4 and more (19). The average 'years of experience' was 14.38 and the median 12 . The standard deviation from the mean was 11.54, while the sum of all respondents' experience was 9220 years.

Participants were given a choice of 20 different specialisations typically found within the water sector. These were originally selected by studying university research structures, water utility and state structures and associated themes and groups. While some of the areas are very specific, others were general, allowing for a mix of responses. To ensure that the level of specialisation was captured, along with the multidisciplinary characteristics of many participants, 3 levels of specialisation were allowed in response (partial understanding, partial specialist and specialist), and multiple responses or areas of specialisations per respondent were allowed.

For each area of specialisation, over 100 respondents indicated they had a partial understanding, while for each area at least 50 respondents stated they were partial specialists (Fig. 4). The largest reduction in responses from partial understanding 


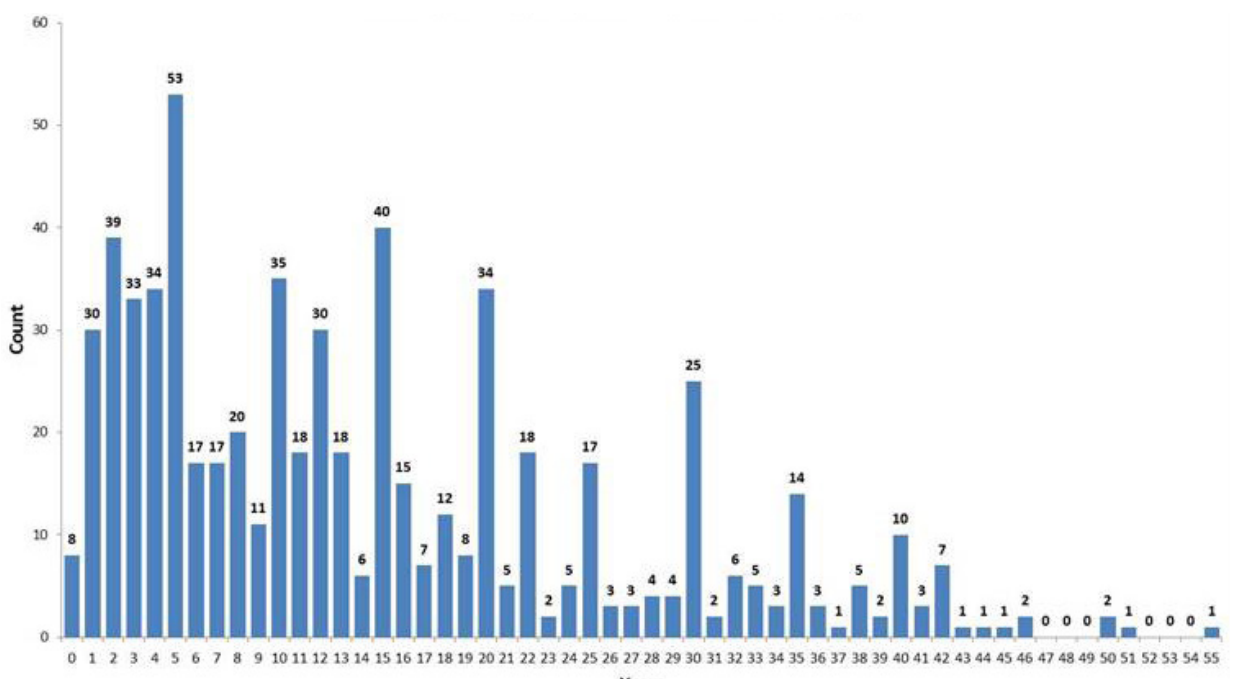

Years

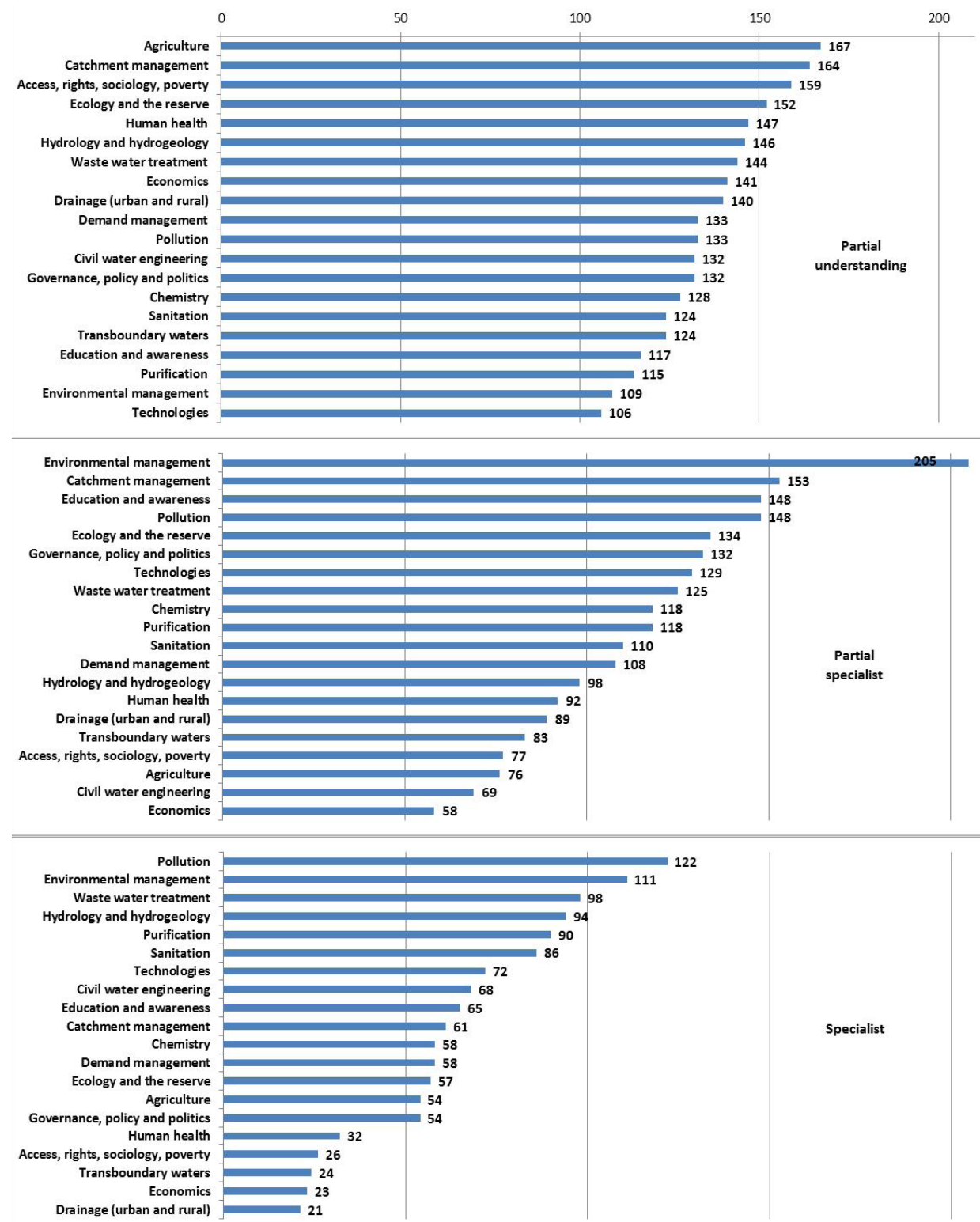

Figure 4

Survey respondent areas of specialisation $(n=641)$ to specialist is observed in the field of economics while the lowest overall responses are observed in: economics (222), transboundary water (231) and drainage (urban and rural) (250), indicating
Figure 3

Survey respondent years of experience in the water sector $(n=641)$ either less survey marketing and access to stakeholders were achieved in these specialisations or simply a reduced number of persons active therein. Environmental management (425), 


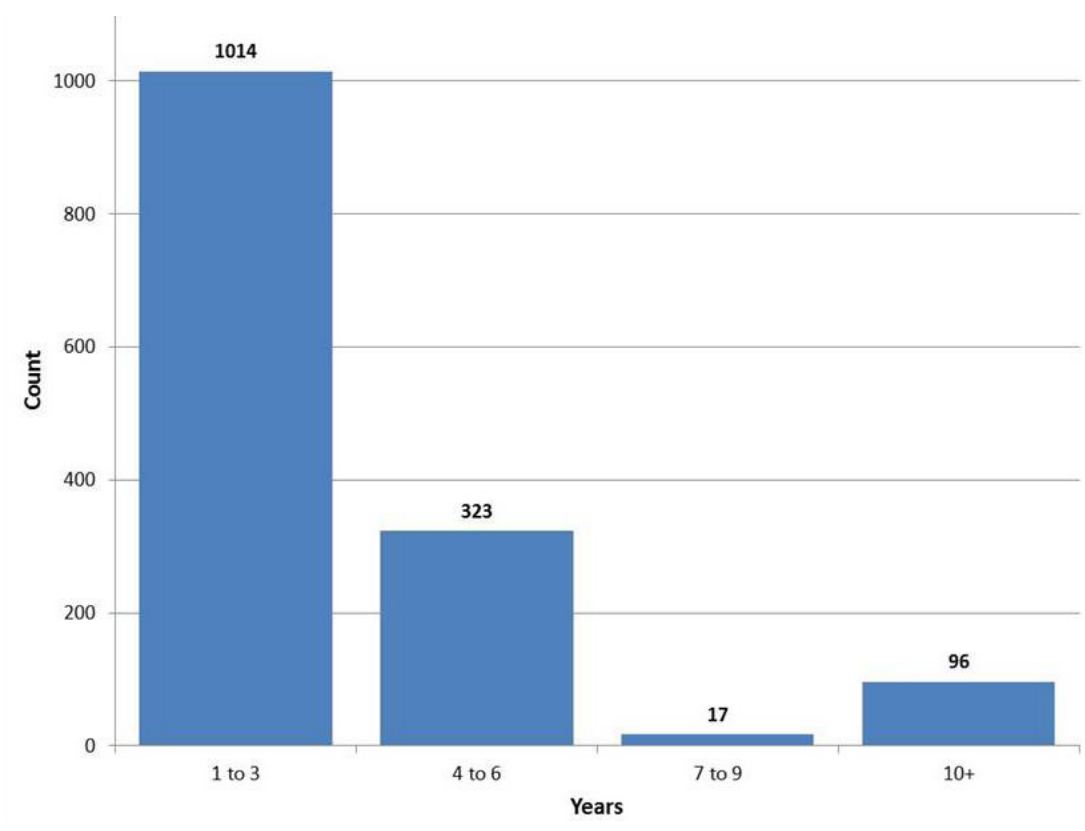

Figure 5

Submitted time duration required to address research questions (responses $=1450)$ pollution (403), catchment management (378) and wastewater treatment (367) show the most consistently high number of responses in all types or specialisation. Total responses for all three types for each area are shown in the label brackets. Overall, there were 2713 responses of partial understanding, 2270 of partial specialist and 1274 responses of specialist.

\section{Priority water research questions}

Respondents were asked to submit 5 water research questions according to the guidelines in the survey. They were also asked to state how long they thought each proposed question would take to answer, what keywords or categories the question related to, and to comment on their question. Of the 641 survey respondents, 125 provided 5 questions, 85 provided 4,104 provided 3, 100 provided 2, 197 provided 1 question and 30 did not provide any questions. This resulted in a total of 1674 questions being captured for consideration during the main survey.

As explained in the above, the questions were edited for basic style, grammar, spelling and question construction. The keyword or category entries and research lengths were then standardised. Of the 1674 questions that were gathered, 1450 were submitted with an approximate research length of time (Fig. 5). The vast majority of the submitted questions (1 014) fall within the 1 to 3 -year category while the mean for the responses was 3.13 with a standard deviation of 2.32 . Approximately 100 questions were claimed to have a research timeframe of over a decade, while 323 questions were projected to take from 4 to 6 years to complete.

Of the 1674 questions submitted, 4629 keywords/categories were provided of which 844 were unique. The complete dataset of originally submitted questions, keywords and lengths (post-basic editing) is available on the research website along with the reduced lists discussed later in the results.

Following a second review of the dataset, 71 questions were removed or merged because they were obvious duplicates of others. This left 1603 questions which were categorised into 6 themes for the workshop. The themes were created from a number of methods: a desktop study of the WRC research and funding structure, an analysis of the National Water Resource Strategy 2012 identifying key strategic areas of intervention, a study of the submitted question keywords, and discussions with invited delegates to the workshop in their pre-event preparation. During the theme construction, 22 cross-cutting issues were identified that could not readily be placed in a theme but appeared prominently in the dataset and analysis (Table 1).

Each question was placed into a theme depending on its main focus or area of inquiry. The numbers of questions per theme were: resources (683), innovation (276), governance (245), change (204), ecosystems (158) and data (34).

This dataset, hereafter referred to as the start list, constitutes a major output from the main survey and overall research effort. Questions that were highly specific to a geographic region or place were removed along with ones that were too broad, vague or general. Following this exercise, questions were tested using a primary rationale for theme acceptance

TABLE 1

Twenty-two cross cutting issues observed in the collected questions

\begin{tabular}{|l|l|l|}
\hline Allocative efficiency & Modelling & Socio-ecological responses \\
\hline Culture & Multi-sector participation & Sustainable development \\
\hline Education & Population growth & Technical and socio-technical \\
\hline Equity & Poverty & Transdisciplinary \\
\hline Food security & Public information & Urbanisation \\
\hline Gender & Rights & Water pricing \\
\hline Goods and services & Risk and vulnerability & \\
\hline Health & Sanitation & \\
\hline
\end{tabular}




\begin{tabular}{|l|l|}
\hline \multicolumn{2}{|c|}{ TABLE 2 } \\
\hline Organisational affiliations of workshop delegates \\
\hline Breede-Overberg Catchment Management Agency & South African Chamber of Mines \\
\hline Department of Agriculture & Trans Caledon Tunnel Authority \\
\hline Department of Water Affairs (3) & Tshwane University of Technology (2) \\
\hline Eskom & University of Cape Town (3) \\
\hline eThekwini Water and Sanitation & University of KwaZulu-Natal (2) \\
\hline Independent consultants/consultancies (5) & University of Pretoria \\
\hline Inkomati Catchment Management Agency & University of Stellenbosch \\
\hline Rand Water & University of the Free State \\
\hline Rhodes University & Water Research Commission (3) \\
\hline Sasol & World Wide Fund for Nature \\
\hline South African Breweries & \\
\hline
\end{tabular}

\begin{tabular}{|l|c|c|c|c|}
\hline \multicolumn{5}{|c|}{ TABLE 3 } \\
& Total and proportional question counts throughout the research \\
\hline & Start list & Long list & Short list & Final list \\
\hline CHANGE & 204 & 55 & 11 & 9 \\
\hline Relative \% & 12.73 & 13.72 & 12.22 & 15.25 \\
\hline DATA & 34 & 35 & 8 & 5 \\
\hline Relative \% & 2.12 & 8.73 & 8.89 & 8.47 \\
\hline ECOSYSTEMS & 158 & 49 & 13 & 7 \\
\hline Relative \% & 9.86 & 12.22 & 14.44 & 11.86 \\
\hline GOVERNANCE & 245 & 76 & 16 & 11 \\
\hline Relative \% & 15.28 & 18.95 & 17.78 & 18.64 \\
\hline INNOVATION & 276 & 83 & 21 & 14 \\
\hline Relative \% & 17.22 & 20.70 & 23.33 & 23.73 \\
\hline RESOURCES & 686 & 103 & 21 & 13 \\
\hline Relative \% & 42.79 & 25.69 & 23.33 & 22.03 \\
\hline TOTAL & 1603 & 401 & 90 & 59 \\
\hline Relative \% & 100.00 & 25.02 & 5.61 & 3.68 \\
\hline
\end{tabular}

of: (i) whether the question lends itself to an obvious research method and process; and (ii) how important the question is for South Africa (either in the short or long term) and what level of knowledge is still required or already known about the issue. This initial reduction exercise interrogated each question individually and was undertaken by the principle investigator on the project. It is accepted that this process could have been more collaborative and systematic but the project budget and scope could not allow for this. It was imperative to reduce the number of questions to a manageable volume prior to the specialist workshop.

This exercise reduced the dataset to 401 questions or $25 \%$ of the initial dataset (hereafter referred to as the long list) and a few questions were moved to different themes upon review which resulted in the following theme number reduction: resources $(683 \rightarrow 103)$, innovation $(276 \rightarrow 83)$, governance $(245 \rightarrow 76)$, change $(204 \rightarrow 55)$, ecosystems $(158 \rightarrow 49)$ and data $(34 \rightarrow 35)$.

\section{Water research horizon scanning workshop}

The 401 questions in the long list provided the input data into the 'Water research horizon scanning workshop'. Following close consultation with the research team, funders and other specialists in the field, 90 invitations were distributed in August 2012 to attend the workshop, to certain initial survey respondents and further selected individuals. Overall, 34 delegates attended the workshop who were affiliated to a range of organisations (Table 2).

The 34 delegates followed a programme which included 2 plenary sessions and a series of small group discussions in which each group considered 3 of the 6 themes on offer. In the small group sessions, delegates were asked to reduce the long list of 401 questions to approximately a quarter of the theme totals. This resulted in 90 questions remaining as priority questions after the first day. These 90 questions, referred to as the short list, were subjected to careful review and editing by the groups in respect of substance and meaning, wording, style and question intent.

The membership of each of the three groups remained the same on the second day, but with the request to consider different data. Each group received the results of the other two groups from the previous day (the short list). Groups were then asked to reduce the theme lists further by approximately half. This final dataset comprised 59 priority water research questions across the 6 themes and is here referred to as the final list.

The long list contained a quarter (25.02) of the opening/ input start list dataset (Table 3). This was further reduced to $5.61 \%$ in the short list and $3.68 \%$ in the final list. The final list consists of the priority $3.68 \%$ water research questions gathered during the main survey.

The final list results, workshop summary, completed datasets and overall project report were placed on the research 
website in December 2012 (www.aquaduct.org.za). All stakeholders in the database were notified via e-mail of the posting of the final results at this time.

\section{RESULTS}

\section{Priority water research questions in South Africa 2012}

The final list is presented below and constitutes the central output of this paper (numbering is for identification purposes only and does not indicate rank). This is a first attempt to build prioritised questions using this method and to present the results in this manner in South Africa. Annual/regular studies or exercises of a similar nature would enable better systems of conducting this research and improve the research design, output and outcomes. Questions are listed within their theme and it is recognised that many questions could have been located across multiple themes.

\section{Theme: Change}

Building socially resilient and adaptive responses to social, climate and general environmental change:

1. How does global change impact water supply and demand, sustainable water services delivery and food security in South Africa?

2. What are the obstacles to achieving sustainable water and sanitation access for all?

3. How can integrated planning and development be implemented in order to deal with rapid rates of urbanisation?

4. What data and information is essential for monitoring hydrological responses to the change drivers for South Africa and how are these data best utilised in the sustainable development of South Africa?

5. In which ways can the efficiency of utilities and municipalities be improved in terms of water and wastewater services delivery?

6. What early warning and response systems need to be put in place to detect emerging waterborne contaminants?

7. How do we ensure that South African water research agenda is relevant and the outcomes adopted and implemented appropriately at a faster rate?

8. What is the strategic value of water and what changes need to be made in the South African economy to accommodate future water scarcity?

9. How can the social perception of the value of water be changed?

\section{Theme: Data}

Capturing of quality data through strategic monitoring, and with reliable analysis, modelling and scientific reporting:

10. How can real-time water data collection be used to act expediently?

11. How can the utility of monitoring systems and networks be optimised, maximised and explained to ensure sustainability of the resource and the monitoring system itself?

12. How and why could society at large contribute to and benefit from open-access data related to water quality and availability?

13. How can rainfall, runoff and hydrological monitoring in South Africa be improved for better use in terms of decision making, planning, management and operations?

14. What is the current and desired state of data collection, use and data-driven accountability in water services authorities?

\section{Theme: Ecosystems}

Protection, conservation, restoration and productive use of healthy ecosystem services:

15. How can biological systems such as bio-filters and wetlands be more effectively (re)used to treat all sources of pollution before it enters the freshwater and marine environment?

16. What is the full ecosystem service value of our water resources and how can it be mainstreamed into the formal economy?

17. What is extent and quantitative impact of alien invasive vegetation on a river's variable hydrology and water quality?

18. What is the ecological impact on communities and the environment of not implementing the ecological Reserve including over-abstraction of water?

19. What are the trends and effects of deteriorating water quality on the ecological function and associated risk and vulnerability of aquatic ecosystems?

20. How can public education more effectively address the possible imbalances and trade-offs between ecological protection and use of water resources?

21. What threats does economic development such as mining pose to the water-related environment?

\section{Theme: Governance}

Integrated, strategic adaptive management:

22. What has slowed the implementation of integrated water resource management in South Africa?

23. How can effective regulation for water and wastewater service provision be achieved in South Africa?

24. How can water resources within catchments be allocated to maximise sustainable economic, social and environmental benefits?

25. How can sustainable business models for catchment management organisations be developed?

26. How can South Africa's water information systems be improved in terms of collection, management and dissemination?

27. What policy and practice mechanisms need to be put in place to successfully implement water demand management and conservation?

28. How can the controls on municipal water treatment in South Africa be improved to reduce the risk to human health?

29. What can be done to reduce river pollution in South Africa?

30. What are the benefits of, and how effective is, ring fencing of water sales and wastewater treatments costs for use in South Africa?

31. What can be done to improve water quality monitoring, control, implementation and enforcement?

32. How do we ensure effective implementation of co-operative governance and regulation specially inter-departmental communication?

\section{Theme: Innovation}

Investment in infrastructure and research for innovation (appropriate technologies, capacity of human resources and infrastructure): 
33. What are the future skills gaps for professionals in the water sector and stakeholders and how can those be effectively addressed and the solutions monitored and integrated into planning and operations?

34. What are the potential opportunities for energy savings in water and wastewater abstraction, treatment, distribution, collection, treatment and management without compromising quality?

35. How can the role of monitoring and information systems assist in the management of the water and wastewater and be well communicated to the public?

36. How can the rural poor effectively access water including sanitised wastewater for productive use?

37. Which upstream and in-stream tools can be developed for the reduction and evacuation of sediment out of rivers, wetlands and dams?

38. To what extent can earth observation and related technologies be further operationalised for applications in agrohydrological cycles in South Africa?

39. How do we develop effective and efficient means of preventing, testing and treating drinking water and wastewater for emerging micro-pollutants and pathogens?

40. How can innovative process technologies, including nanotechnology, be applied to benefit water and wastewater treatment processes?

41. How do we urgently, effectively and efficiently reduce water and wastewater losses in South Africa in a sustainably and socially just manner?

42. How can we move towards sustainable urban drainage systems to accommodate flood events under present and projected climate change situations?

43. What is the most cost effective and hygienic technology for treating sanitary waste, solid waste and greywater disposal in low-income and informal settlements?

44. How can urban planning and implementation be used to provide cities and towns with safe, efficient and secure water, wastewater and stormwater distribution and collection systems?

45. What are the governance systems that need to be implemented in order to reduce and control eutrophication and how are they best implemented in the South African context?

46. How should urban planning and implementation be used to provide efficient water, stormwater, greywater and wastewater cascading and reuse considering separation at source including separation of solid waste?

\section{Theme: Resources}

Protection, conservation, treatment and management of water resources for equitable growth and development:

47. What are the policy and management approaches (agronomical, soil fertility management, water quality, nutrient reuse and greywater reuse) that can optimise water use efficiency in agriculture?

48. To what extent are current water pricing policies not encouraging efficient resource utilisation?

49. What systemic relationships exist between South African water quality, quantity and human diseases and how can these be addressed?

50. What is the effect of large-scale hydraulic fracturing and related activities for gas extraction in the Karoo on the future groundwater quality and ecosystems in South Africa?
51. What policies must be implemented to ensure effective water demand management?

52. How can water footprinting tools and frameworks improve the knowledge and assessment of competing water uses and risk?

53. How best should we quantify the economic value of water to address competing demands to ensure equitable and sustainable growth and development in the contexts of growing water scarcity?

54. What are the life cycle and systematic impacts of acid mine water and how can these be managed, mitigated, remediated and beneficiated?

55. How can urban South Africa transition towards watersensitive resilient cities?

56. What mechanisms can be used to detect and address the current and future priority emerging contaminants in South Africa?

57. How can groundwater resources be further developed, utilised, and managed in a sustainable manner?

58. What are the health implications of irrigating various crops and watering of livestock with polluted water?

59. What are the most effective methods in handling illegal water use?

\section{DISCUSSION}

The strategies undertaken by the Aqua d'UCT initiative surpassed expectations with regards to participation, uptake and response. The diverse nature of the results and interaction during the study occurred mainly with a growth from over 600 to over 2000 stakeholders on the research contact database in the year 2012. The largest proportion of the stakeholders was captured through self-sign-up, pointing towards a genuine interest in the study and initiative. The activities during key events and surveys showed that the catchment of research stakeholders can be increased and a strong representation of water research interests in South Africa is captured on the contact database. Stakeholders include different sectors such as the state, research organisations, universities, the private sector and civil society or interest groups. Substantial feedback was gathered through the pilot survey processes on how to better manage and attract diverse stakeholders. Participants and respondents in the main survey represented diverse occupations or career types, from management, to pure research to advisory. They were an interdisciplinary and mixed group of stakeholders and were representative of the South African water research and practice community. The dispersed and oftentimes substantial years of experience and high diversity in stated areas of specialisation strengthened the diversity.

While many respondents called for longer and more substantial research projects to be funded and established, the majority of research questions submitted were labelled as only requiring 1 to 3 years to complete. This contradiction underlines the disjuncture between what respondents thought was required and what was practical in reality. These questions were nevertheless placed in many diverse research disciplines and specialisations as seen by the keywords attached to them by respondents. Research relating to non-technical domains of management, governance, planning, education, policy, and alternatives were prominent in the keyword count. However, the predominance of technical questions relating to treatment, quality and pollution, hydrology, climate, supply and ecology provided an even stronger motivation to assign the questions to broad themes as seen in the results. 
From the final list, technical and social aspects of water are inquired about and the questions do align to their respective themes. Many are, however, coupled or integrated questions that cover a few disciplines and can be housed in alternative themes with slight adjustments in emphasis. These represent many future priority challenges that research needs to approach. The scale and scope of questions were not addressed in this final prioritisation method and many questions deal with immediate concerns while others aim to tackle long-term or systemic problems. The nature of the horizon within these questions could not be seen clearly. Delegates instead focused on prioritisation within present and future needs and ensured that a level of balance existed in the final results.

The workshop was evaluated by delegates on closing and was acknowledged by many as an energising and interesting collaborative exercise. While there were some obvious gaps in the representation, delegates were pleased to interact with diverse leaders in the field. The quality and high level of exchange and interaction during the formal and informal activities was embraced and many identified this as a key feature of the experience. The structured approach to the workshop made the best use of time in order to achieve the intended product, yet delegates were nevertheless frustrated by the pressure to modify a large set of questions that appeared to have limited value to them at the time.

The strongest criticism was that the approach and methods used at the workshop were not designed to identify horizon scanning research questions in themselves. Rather delegates felt that they were coerced into responding to the questions that were put before them. Moreover, delegates claimed that it was difficult to develop new questions that were of an horizonscanning nature for a number of reasons: the groups were too diverse; there was insufficient time to consider and develop meaningful questions; and the process was too demanding for the facilitators which tended to result in tasks being carried out in a mechanistic manner and all within a tight timeframe. In addition, delegates complained that they had to work with a large number of questions which were poorly formulated.

Problematic questions came in a number of forms: they were often about immediate issues; they could not be identified as a research question; they were too broad to be categorised in a chosen theme; were often limited to disciplines and fields within the natural sciences; and many did not show any insight into what might lie on the horizon.

\section{Substantive assumptions and limitations}

Horizon scanning has numerous potential limitations and opportunity for error due its active, action research nature and complex socio-political context. It is recognised that this methodology exists within a social, political and cultural space where interaction with stakeholders occurs constantly, thus making the process and its success unpredictable.

The single most significant limitation was that more stakeholders could not be involved in the research directly. This would have provided more data and questions, and wider representation of water researchers in South Africa. Nevertheless, the main survey and specialist workshop response rates were high enough for drawing meaningful results and analysis. It is assumed that participants submitted their responses to the best of their knowledge and ability; did not intentionally provide false answers; and were able to be as honest as possible. The use of electronic responses and guaranteeing data security and participant anonymity aided in this process.

\section{CONCLUSION}

The question prioritisation activities using horizon scanning methods promoted interaction with a wide and diverse population of water research stakeholders and practitioners. Digital tools increased the reach of the study and allowed for faster communication and results dissemination, resulting in a growth from 600 to over 2000 stakeholders on the research contact database in the year 2012. The use of brand development and digital media aided this growth and is strongly recommended for studies of a similar nature.

The survey results are a substantial collection of research questions from water stakeholders and researchers. The process of reducing the survey dataset to a final priority list was rigorous. Here the reduction from 1603 initial, to 59 priority research questions for water, represent many technical, social and interdisciplinary areas of questioning. Many questions deal with immediate concerns while others aim to tackle mediumterm or systemic problems and few approach long-term challenges. Others are coupled or integrated questions that cover several disciplines. It is recognised that short-term research can accumulate value and provide solutions for long-term challenges but these challenges on the horizon are poorly represented in the results.

Upon reassessment of the method, feedback and the final list of questions, the results are seen to have significant value as a collection of national research priorities that was derived from a collaborative process. While the priorities were not focused exclusively on the horizon, they still capture the knowledge needs within the field of water research through actionable research questions. The results can be used for research planning and strategic management. These questions also indicate the current state of thinking amongst researchers and a wide range of stakeholders with an interest in water resources.

Significant limitations did exist within the study. Horizon scanning has many inappropriate elements for the South African context as it is limited to a degree by its reach and participation. It is recommended that further prioritisation activities are undertaken to guide research but that these could be initiated by specialists first before extending the consultation process to a wider audience. The adapted methods and definitions of horizon scanning also need to be further interrogated within the local context before future work is undertaken. The current state of questioning does, however, provide an overall perspective of what a large and diverse group of research stakeholders and practitioners are asking even if the questions may not all be on the horizon.

The results of the study represent a collaboratively derived collection of national research priorities. It appears that this is the first effort of its kind to produce a comprehensive and inclusive list of research priorities for water in South Africa. If the study does no more than generate lively debate around the process and the priority questions, it will have served its purpose well by bringing the discussion of long-term water research organisation and planning to the fore.

\section{ACKNOWLEDGEMENTS}

This publication was based on the Water Research Commission funded project K5/2170. The project leaders wish to thank the invaluable input of the reference group participants; the workshop delegates who gave of their time to prioritise research questions and debate research in South Africa; and the project staff who contributed in their specific tasks and fields. 


\section{REFERENCES}

BARBIER E and HOMER-DIXON T (1996) Resource scarcity, institutional adaptation, and technical innovation: can poor countries attain endogenous growth? Occasional Paper Project on Environment, Population and Security. American Association for the Advancement of Science, Washington \& University of Toronto, Toronto.

BORTOLOTTI L (2008) An Introduction to the Philosophy of Science. Polity Press, Cambridge.

BROWN L, MITCHELL G, HOLDEN J, FOLKARD A, WRIGHT N, BEHARRY-BORG N, BERRY G, BRIERLEY B, CHAPMAN P, CLARKE $S$ and co-authors (2010) Priority water research questions as determined by UK practitioners and policy makers. Sci. Total Environ. 409 256-266.

CASH D, CLARK W, ALCOCK F, DICKSON N, ECKLEY N, GUSTON D, JAGER J and MITCHELL R (2003) Knowledge systems for sustainable development.Proc. Natl. Acad. Sci. 100 (14) 8086-8091.

DEPARTMENT OF WATER AFFAIRS (2012) National Water Resource Strategy 2012. URL: www.dwa.gov.za/nwrs/nwrs2012 (Accessed 1 September 2012).

EUROPEAN ENVIRONMENT AGENCY (2001) Late lessons from early warnings: the precautionary principle 1896-2000. Environmental Issue Report no 22. Office for Official Publications of the European Communities, Copenhagen.

FUNKE N, NORTJE K, FINDLATER K, BURNS M, TURTON A WEAVER A and HATTINGH H (2007) Redressing inequality: South Africa's new water policy. Environment 49 (3) 10-23.

HOMER-DIXON T (1995) The ingenuity gap: can poor countries adapt to resource scarcity? Popul. Dev. Rev. 21 (3) 587-612.

KING D and THOMAS S (2007) Taking science out of the box - foresight recast. Science 316 1701-1702.

PRETTY J, SUTHERLAND W, ASHBY J, AUBURN J, BAULCOMBE D, BELL M, BENTLEY J, BICKERSTETH S, BROWN K, BURKE
$J$ and co-authors (2010) The top 100 questions of importance to the future of global agriculture. Int. J. Agric. Sustainability 8 (4) 219-236.

PULLIN A, KNIGHT T and WATKINSON A (2009) Linking reductionist science and holistic policy using systematic reviews: unpacking environmental policy questions to construct an evi dence-based framework. J. Appl. Ecol. 46 970-975.

REPUBLIC OF SOUTH AFRICA (1971) Water Research Act (No. 34 of 1971). Government Printer, Pretoria.

REPUBLIC OF SOUTH AFRICA (1998) National Water Act (No. 36 of 1998). Government Printer, Pretoria.

SHACKLETON C, SCHOLES B, VOGEL C, WYNBERG R, ABRAHAMSE T, SHACKLETON S, ELLERY F and GAMBIZA J (2011) The next decade of environmental science in South Africa: a horizon scan. S. Afr. Geogr. J. 93 (1) 1-14.

SUTHERLAND W and WOODROOF H (2009) The need for environmental horizon scanning. Trends Ecol. Evol. 24 (10) 523-527.

SUTHERLAND W, BARDSLEY S, BENNUN L, CLOUT M, CÔTÉ I, DEPLEDGE M, DICKS L, DOBSON AP, FELLMAN L, FLEISHMAN E and co-authors (2011a) Horizon scan of global conservation issues for 2011. Trends Ecol. Evol. 26 (1) 10-16.

SUTHERLAND W, FLEISHMAN E, MASICA M, PRETTY J and RUDD M (2011b) Methods for collaboratively identifying research priorities and emerging issues in science and policy. Meth. Ecol. Evol. 2 (3) 238-247.

TEWARI D (2009) A detailed analysis of evolution of water rights in South Africa: An account of three and a half centuries from 1652 AD to present. Water SA 35 693-710.

TREYER S (2009) Changing perspectives on foresight and strategy: from foresight project MANAGEMENT to the management of change in collective strategic elaboration processes. Technol. Anal. Strat. Manage. 21 (3) 353-362.

TURTON A (2009) The role of science in deepening democracy: the case for water in post-Apartheid South Africa. J. Transdisciplinary Res. S. Afr. 5 (1) 9-28. 
http://dx.doi.org/10.4314/wsa.v40i2.2 Available on website http://www.wrc.org.za

ISSN 0378-4738 (Print) = Water SA Vol. 40 No. 2 April 2014 ISSN 1816-7950 (On-line) = Water SA Vol. 40 No. 2 April 2014 